\title{
ALK/FAK/Pyk2 Inhibitor CT-707
}

National Cancer Institute

\section{Source}

National Cancer Institute. ALKIFAK/Pyk2 Inhibitor CT-707. NCI Thesaurus. Code C126648.

An orally available inhibitor of the receptor tyrosine kinase anaplastic lymphoma kinase (ALK), focal adhesion kinase (FAK) and proline-rich tyrosine kinase 2 (Pyk2), with potential antineoplastic activity. Upon administration, ALK/FAK/Pyk2 inhibitor CT-707 selectively binds to and inhibits ALK, FAK and Pyk2. The inhibition leads to disruption of ALK- , FAKand Pyk2-mediated signal transduction pathways and eventually inhibits tumor cell growth in ALK-, FAK- and Pyk2-overexpressing tumor cells. Expression of these tyrosine kinases is dysregulated in various tumor types; they play a key role in tumor cell migration, proliferation, survival, and tumor angiogenesis. 